\title{
Homo infantilis: asimilación y segregación en la política colonial española en Guinea Ecuatorial
}

\author{
RAÚl SÁNCHEZ MOLINA \\ Dpto. de Psicología Social y Antropología \\ Universidad de Salamanca
}

RESUMEN

La construcción etnocéntrica del otro como bomo infantilis fue utilizada ideológicamente por los europeos para justificar políticas coloniales. El caso particular de la política indígena española en Guinea Ecuatorial nos ofrece un ámbito socio-cultural singular para analizar algunos de los significados y las funciones políticas de esta imagen durante el primer franquismo. Este ánalisis nos permite profundizar en el alcance de algunas políticas coloniales desarrolladas por los europeos en el continente africano, como la asimilación y el desarrollo de fenómenos sociales modernos como el racismo.

Palabras clave: Colonialismo, Asimilación, Racismo, Guinea Ecuatorial.

\section{SUMMARY}

The otherness' ethnocentric construction such as bomo infantilis was used by Europeans to justify colonial policies. Spanish colonial policies in Equatorial Guinea provide us a significant context to analyze this specific colonial image's socio-cultural meanings. This article seeks to understand some of this image's political meanings and functions during the Franco colonial period in Equatorial Guinea. This analysis throws some light upon some colonial policies, such as assimilation, implemented by some European countries in Africa as well as some modern social phenomenon such as racism.

Key words: Colonialism, Assimilation, Racism, Equatorial Guinea.

Una de las consecuencias sociales del actual proceso de globalización es el desplazamiento de un número importante de personas procedentes de países anteriormente colonizados hacia las antiguas metrópolis europeas. Este fenómeno social está configurando nuevos espacios pluriculturales en muchas poblaciones europeas; al tiempo que se suceden debates y reacciones sobre las estrategias políticas que han de emplearse para integrar a las poblaciones recién llegadas (Portes y Rumbaut 1996; Todd

RDTP, LVII, 2 (2002): 105-120 
1996; Malgesini 1998). Esta situación de "ida y vuelta" trae de nuevo a colación el lastre y las secuelas de políticas coloniales - no tan lejanas en el tiempo- que hicieron posible el desarrollo de fenómenos sociales modernos, como el racismo, a través de construcciones ideológicas que pretenden justificar, con categorías cientifistas, prejuicios eminentemente etnocéntricos (King 1997) ${ }^{1}$. De ahí el lugar central que en los estudios antropológicos ha tomado, desde la década de 1960, la situación colonial como contexto de partida para comprender algunos de estos desajustes socio-culturales que tradicionalmente han impedido el reconocimiento de la diversidad cultural (Leclerc 1972; Gallo 1988; Comaroff 1991; Asad 1992).

La situación colonial propició el desarrollo de nuevas realidades multiculturales sobre principios y relaciones de dependencia que, en el caso del continente africano, se dieron como consecuencia de la expansión del capitalismo europeo en la segunda mitad del siglo XIX. Con la ideología de la denominada "misión civilizadora", la construcción etnocéntrica del otro no-europeo como bomo infantilis se utiliza como elemento ideológico con el que justificar la expansión política-económica en el continente, y como consecuencia, el sometimiento de su población a las nuevas leyes de los gobiernos coloniales (Curtin 1964; Leclerc 1972; Comaroff 1991). Estos esfuerzos de reducción de la alteridad a una "minoría de edad" no hacían más que continuar, con nuevas categorías de carácter científico, una tradición de desplazamientos, exclusiones y negaciones de la diferencia cultural que se había iniciado siglos antes en el continente americano (Bartra 1996). De ahí que en el caso particular de las políticas coloniales españolas en los territorios del Golfo de Guinea, y sus esfuerzos ideológicos por justificarlas, encontremos un ámbito altamente significativo para analizar la continuidad y los cambios de estas imágenes coloniales, instrumentalizadas en los distintos esfuerzos políticos de homogeneización socio-cultural (Negrín 1993; Sánchez 1998). Estos esfuerzos, basados en cualquier caso en la falta de reconocimiento de la diferencia cultural, desembocan inevitablemente en políticas asimilacionistas de exclusión. Es decir, sobre la falta de reconocimiento de las diferencias culturales, se imponen los patrones culturales de la población dominante (Kottak 1994: 56). Sobre estas bases, este artículo intenta analizar algunos de los significados y de las funciones de la imagen del bomo infantilis en contextos coloniales; centrando la atención en la política indígena

\footnotetext{
${ }^{1}$ En este artículo se consideran políticas racistas todas aquellas prácticas vinculadas a doctrinas propias del pensamiento moderno occidental que intentan justificar y legitimizar como natural una estructura jerárquica entre las poblaciones en función de posibles diferencias biológicas y psicológicas (Moreno 1994).
} 
durante el periodo del primer franquismo (1938-1959). La significativa producción literaria de carácter colonial publicada durante esta época constituye una fuente de gran valor para este propósito ${ }^{2}$. Estas mismas fuentes nos permiten reconstruir distintos contextos en los que esta imagen aparece como apoyo a una política de asimilación que, en cualquiera de las situaciones, se muestra ambigua y contradictoria.

\section{LA DIVERSIDAD CULTURAL Y LA POLÍTICA INDÍGENA}

La expansión europea en la costa occidental del continente africano propicia en el transcurso del siglo XIX la formación de sociedades multiculturales en distintos asentamientos de la costa atlántica, de la misma manera que el colonialismo europeo lo había propiciado siglos antes en el continente americano (King 1997). En el caso de Guinea Ecuatorial, en la isla de Bioko, habitada por los bubis, se forja - a partir de la década de 1820 - el desarrollo de una sociedad multicultural con la llegada de distintos grupos procedentes de lugares cercanos del continente; fundamentalmente como consecuencia de la persecución británica del tráfico de esclavos (Castro y Calle 1992). Durante este periodo, las naves británicas desembarcan en Malabo - ciudad fundada entonces por los ingleses como Clarence- africanos liberados de la trata de esclavos y colonos procedentes de Sierra Leona. Esta incipiente población dará origen a la población criolla de los fernandinos ${ }^{3}$. Después de varios intentos de colonización española, llegan definitivamente para establecerse en la isla - a partir de 1858- los primeros administradores y misioneros españo-

\footnotetext{
${ }^{2}$ Durante el franquismo se llevaron a cabo distintas investigaciones de carácter científico que fueron publicadas por el Consejo Superior de Investigaciones Científicas, fundamentalmente, en la revista Archivos del Instituto de Estudios Africanos (IDEA). En el ámbito de la antropología, en esta revista se publican las primeras investigaciones etnográficas españolas sobre el continente africano llevadas a cabo, entre otros, por Julio Caro Baroja, Carlos González Echegaray, Augusto Panyella o Claudio Esteva Fabregat (Calvo 1997; Sánchez 1998). Asimismo, los misioneros claretianos continuaban editando quincenalmente su revista La Guinea Española, fundada en 1903, con artículos de interés colonial. Estas publicaciones constituyen fuentes importantes para cualquier investigación sobre este periodo colonial.

${ }^{3}$ El capitán William F. Owen traslada, en 1827, desde Sierra Leona unas 150 personas entre colonos y trabajadores, contratados éstos por un año para construir la ciudad de Clarence, rebautizada por los españoles como Santa Isabel de Fernando Poo y actualmente Bioko, la capital de Guinea Ecuatorial. En la década de los treinta y cuarenta continúan llegando libertos y trabajadores de Sierra Leona, de tal manera que la ciudad va creciendo a pesar del alto índice de mortandad en la isla (Castro y Calle 1992).
} 
les, a los que seguirán unos años más tarde libertos y deportados políticos procedentes de Cuba. Asimismo, los primeros fang de la parte continental de Río Muni comienzan su asentamiento en la isla de Bioko de la mano de los misioneros (Pujadas 1983). Durante la primera mitad del siglo $\mathrm{xx}$, la población de la isla, mayoritarimente bubi, aumenta con la llegada de trabajadores temporales procedentes primero de Liberia y, posteriormente, de Nigeria, reclutados por colonos europeos para trabajar en la agricultura y en la industria maderera. Al mismo tiempo, se inician los primeros intentos militares de colonización de la parte continental de Río Muni, coincidiendo con el progresivo proceso migratorio de los fang hacia el litoral, entonces habitado por poblaciones costeras como los ndowes, bengas, combes, bujebas o balengues (Chamberlain 1978; Fernandez 1982). Este complejo proceso de formación social propiciada por el colonialismo - difícil de sintetizar en tan poco espacio- explica la existencia de una singular sociedad multicultural que habita Guinea Ecuatorial durante el franquismo: poblaciones autóctonas, inmigrantes de la parte occidental del continente y europeos, principalmente españoles y portugueses ${ }^{4}$.

En los albores del siglo xx, los territorios del Golfo de Guinea se declaran oficialmente colonias de explotación económica; considerando a sus distintas poblaciones como el instrumento prioritario para llevar a cabo tal explotación ${ }^{5}$. Entonces se inicia, en 1904, la política indígena, siguiendo modelos institucionales del colonialismo americano como el Patronato de Indígenas. Esta institución colonial estaba dirigida por una Junta de Patronos representada por el Gobernador General como presidente, el Vicario Apostólico (obispo titular) como vicepresidente y secretario general, el Subgobernador de la parte continental (Río Muni), el delegado de Hacienda y dos delegados de Asuntos Indígenas. Los objetivos oficiales de la institución fueron desde sus inicios: "proteger a los niños o indígenas" y "fomentar la cultura y moralización de los naturales del país y su adhesión a España ${ }^{6}$. Para que esta función tutelar pudiera llevarse a efecto,

${ }^{4}$ Las poblaciones autóctonas estaban representadas por los bubis, fang, fernandinos, annoboneses, corisqueños, bengas, combes, bujebas o balengues. La población inmigrante africana por trabajadores liberianos, luso-africanos, cameruneses, hausas o nigerianos procedentes del Calabar. Y la población europea fundamentalmente por españoles funcionarios, misioneros, colonos agrícolas y forestales, comerciantes y trabajadores (Pélissier 1964; Sundiata 1990).

5 Real Decreto Orgánico de la Administración de las Posesiones españolas del África Occidental (1904). Madrid: Ministerio de Estado (AGA, C-3, n. 9 9, p. 6). En los Archivos de la Administración de Alcalá de Henares.

${ }^{6}$ Real Decreto Orgánico de la Administración de las Posesiones españolas del África Occidental (1904). Madrid: Ministerio de Estado (AGA, C-3, n.ำ 9, p. 18). 
la legislación colonial reducía a todos los africanos de la colonia a la categoría de indígenas, siguiendo el patrón de las Leyes de Indias. Con el inicio de esta política indígena, el Patronato de Indígenas queda con la exclusiva competencia de otorgar la ciudadanía española a la población africana de los territorios, anulando la anterior normativa de 1888 que otorgaba este estatus a todos aquellos africanos bautizados?

En función de su capacidad jurídica, el término indígena ya había aparecido en legislaciones anteriores en los territorios guineanos, con el propósito de proteger las tierras y bienes inmuebles de la población africana y siguiendo lo establecido en distintas leyes americanas del Código de Indias. En la nueva normativa de 1904 el término se especifica como sinónimo de "no-evolucionado". De ahí que el Patronato de Indígenas se convierta, suplantando la capacidad jurídica de los africanos, en una institución tutelar promotora de la asimilación. El Patronato de Indígenas sufriría, no obstante, dos reestructuraciones importantes en 1928 y 1938. La legislación de 1928 divide legalmente la población africana de los territorios, mediante categorías tomadas de la legislación esclavista de las ex-colonias antillanas, en no-emancipados, y, por lo tanto, sometidos a la tutela del Patronato de Indígenas, y en emancipados que, con los mismos derechos que el resto de los españoles, podrían quedar liberados del tutelaje de la institución ${ }^{8}$. El africano no-emancipado quedaba incapacitado - sin la expresa autorización de la Junta de Patronos- para enajenar sus bienes inmuebles, contratar préstamos sobre sus posesiones, comparecer en juicios y contraer obligaciones de carácter económico. Con todo, a pesar de estas regularizaciones normativas, esta institución no alcanzó su definitiva estructuración y su máxima importancia política hasta la época franquista, a partir de la publicación de sus últimos estatutos en 1938. Y es que hasta entonces, la organización judicial de los territorios había sido ambigua y vacilante, debido fundamentalmente a la escasez de personal y de presupuestos administrativos (Zaragoza 1963: 73). De ahí que sea durante las primeras décadas del franquismo cuando el Patronato de Indígenas se convierta en la institución colonial más importante de los territorios como representante de las poblaciones africanas ante la administración colonial. Es decir, en una institución tutelar de las poblaciones africanas, supuestamente transitoria, en su proceso de asimilación.

\footnotetext{
7 Real Decreto del 17 de febrero de 1888.

${ }^{8}$ El concepto de emancipación había aparecido por primera vez en la legislación guineana en un decreto fechado el 24 de julio de 1864, referido a los antiguos esclavos cubanos emancipados que llegaron a la isla de Bioko para reforzar la colonización española de la isla. Con esta nueva legislación, sin embargo, la emancipación podía ser plena o limitada, según la valoración que se hiciera de su asimilación cultural y de su nivel adquisitivo.
} 
Como señalara Juan de Miguel Zaragoza, la reducción de la diversidad cultural que realizaban estas normativas se fundamentaba en dos principios metajurídicos evidentemente restringidos: la existencia del indígena como hecho y, en consecuencia, su valoración a efectos administrativos mediante la imposición de una unidad supraétnica que se fuerza con elementos artificiales para poder hacer efectiva su aplicación legal. En este sentido, se trata de artificialidades metajurídicas que se realizan desde principios raciales y culturales. Desde el punto de vista racial, en cuanto que se atribuye al africano, usando supuestos biologicistas, una normativa específica que contradice en la práctica los principios asimilacionistas a los que aspiraba. Y cultural, en cuanto que parte de una abstracción y simplificación en categorías de rango inferior, tanto de las distintas poblaciones autóctonas (bubis, fang, ndowes...) como de las poblaciones alóctonas desplazadas a la colonia para trabajar en las explotaciones económicas (Zaragoza 1963: 65). Como consecuencia de esta normativa, el Patronato de Indígenas se convierte en el único garante de un régimen tutelar, cuya finalidad teórica es la protección y la creación de unas condiciones específicas para asegurar la asimilación a través de la educación y la evangelización católica.

Por otra parte, las distintas normativas de la política indígena alienan a los africanos de derechos fundamentales como el ius soli o el ius sanguinis. En el primer caso, al no tener en cuenta el derecho de procedencia de los distintos grupos africanos, y por lo tanto, sus diferencias socio-culturales. Y en el segundo caso, al alienar a las poblaciones africanas de sus patrones de filiación que, en cualquier caso, dejaban abierta la posibilidad de divisiones familiares a efectos legislativos. De esta manera, la política indígena no hace más que institucionalizar, a través de una irremediable dependencia de los africanos del Patronato de Indígenas, la concepción del otro como homo infantilis apoyándose en una tradición eurocéntrica basada en lógicas asimilacionistas incapaces de valorar las diferencias culturales, en cuanto que uno de los supuestos legales que se establecen para que los africanos puedan adquirir el estatus de emancipado y, consecuentemente, el derecho de ciudadanía, es la adquisición de la lengua y la cultura española como se señala en los siguientes apartados.

\section{LA ASIMILACIÓN DURANTE EL FRANQUISMO}

Como se ha señalado anteriormente, la política indígena se activa fundamentalmente durante el franquismo. Durante esta época, la asimilación 
o "españolización" reaparece como un ideal de homogeneización socio-cultural importado de un pasado colonial idealizado (Phelan 1958; Paynem 1984). Sin embargo, debemos destacar que estas pretensiones asimilacionistas, defendidas fundamentalmente por los misioneros y algunos destacados administradores, chocan —como ya sucediera en épocas anteriorescon la oposición de algunos sectores, sobre todo colonos con importantes intereses económicos en el territorio africano, proclives a políticas mucho más segregacionistas en su sentido más racista (Negrín 1993). En efecto, mediante planteamientos evolucionistas de carácter determinista, estos sectores cuestionan los principios asimilacionistas al considerar que los africanos no poseen las capacidades psicobiológicas suficientes para la asimilación. Con todo, y a pesar de las divergencias ideológicas, tanto los defensores de la asimilación como sus detractores mantienen en sus posturas la concepción del otro no-europeo como bomo infantilis; subordinado desde paradigmas etnocéntricos, en cualquiera de los casos y de forma más consciente o inconsciente, a los intereses políticos y económicos del sistema colonial.

Durante el franquismo, la restauración tradicionalista que el régimen impone propicia la revalorización de elementos característicos del viejo sistema colonial. El catolicismo reaparece entonces en el escenario colonial guineano - tras las políticas vacilantes de la II República- como el instrumento ideológico y político más importante en el ámbito de la asimilación (Pélissier 1964; Negrín 1993). Esta situación propicia que la asimilación se justifique desde argumentos que podríamos definir como neo-escolásticos, en cuanto que la evangelización católica se concibe en su sentido más tridentino. En este sentido, el otro, no-católico y no-europeo, se contempla en una contradictoria ecuación que opera la idea del bomo infantilis con la del imago Dei:

La política colonial de España tuvo, por tanto, que fundamentarse en esa igualdad, que es esencial, pese a las diferencias más o menos accidentales de color y de raza [...] Sólo existe una diferencia. Mientras que el pequeño no llega a su mayoría de edad es incapaz de ejercitar personalmente sus derechos y disfrutar de ellos plenamente, y está sujeto a la patria potestad y a la tutela [...] (Permuy 1954: 405-406).

\footnotetext{
9 Tanto segregación como discriminación describen políticas y prácticas sociales que perjudican a los miembros de un grupo social concreto. Siguiendo a Conrad Kottak, la discriminación puede ser de dos tipos: tanto de facto, cuando estas políticas y prácticas sociales se ejercen sin estar legalizadas; o de jure, cuando están legitimadas por la ley como en el caso del apartheid sudafricano (Kottak 1994: 62).
} 
Desde esta posición, la idea del homo infantilis continúa apoyándose en la tradicional concepción monogenista escolástica que durante siglos había justificado las políticas indigenistas en el continente americano:

"A priori" los españoles pensamos que el indígena, que es un hermano nuestro, porque del mismo barro nos hizo Dios a todos, no es por eso nuestro igual, sino que está en condiciones de inferioridad con respecto a nosotros, y puesto que lo está, y puesto que es nuestro hermano, tiene derecho y le debemos protección y amparo (Bonelli 1947: 11).

Desde esta perspectiva, el Inspector de Educación de la colonia, Heriberto R. Álvarez, diseña una política educativa enraizada en la tradición colonial americana con el apoyo político del gobernador Juan María Bonelli y la colaboración educativa de los misioneros. Sin embargo, durante este periodo, estas pretensiones asimilacionistas se encuentran, como señalamos anteriormente, con la oposición de los sectores económicos más importante de los territorios que utilizan argumentos evolucionistas, en su sentido más biologicista, para protestar contra esta política asimilacionista:

La afirmación, rigurosamente científica de que el indígena es un ser biológica y psíquicamente inferior, dentro de la especie, no constituye una sorprendente novedad. Pero el hecho de que esta observación haya sido tenida en cuenta al elaborar los sistemas pedagógicos aplicables al negro no se nos ofrece con la misma evidencia (Iglesias 1947: 38).

Partiendo de interpretaciones mendelianas, basadas en la idea de que la inteligencia de los africanos se estanca a partir de la pubertad, plantean un cambio de dirección en la legislación colonial:

Siendo el indígena, por su condición racial, un ser falto de conciencia y de lucidez intelectual para interpretar el origen de los hechos, con carencia casi absoluta del sentido moral, teniendo por brújula el instinto [...] hay que crear otro tipo de leyes diferentes a las del hombre de mediana inteligencia (Banciella: 1940: 48).

La herencia biológica se considera, por lo tanto, un factor determinante que puede llegar a amenazar los intereses de la colonia. Jesús Fernández Cabeza afirma en su libro La persona pamue desde el punto de vista biotipológico (1951) que, al desconocerse los caracteres desfavorables de los fang y teniendo en cuenta sus relaciones exogámicas, la administración colonial tendría que evitar su mestizaje mediante una reelaboración de la legislación vigente:

Poco podemos hacer para variar la dotación hereditaria. Además, no conocemos con seguridad lo que significa la herencia en los caracteres desfavorables del pamue, y es necesario hacer el estudio profundo de esta faceta. Razón por la que 
nos parece inadecuada una intervención que facilite el mestizaje con otros negros, de grupos étnicos que en otros ambientes parezcan superiores, porque tal vez las circustancias peristáticas de nuestra Colonia no resultaran favorables (ya pudieran no serlo las combinaciones de genes), dando origen a unos bastardos indeseables y entrada en nuestro territorio a doctrinas y perjudiciales (Fernández 1951: 76-77).

Este grupo opositor a la asimilación utiliza, igualmente, como apoyo científico a sus tesis, los resultados de investigaciones psicométricas llevadas a cabo en la colonia durante la década de los cuarenta; empleando sus resultados, poco propicios para la asimilación, como argumento contra la política emprendida por Heriberto R. Álvarez. En cualquier caso debe resaltarse que la psicometría en las colonias llevaba décadas ocupando el espacio que habían dejado las investigaciones craneométricas decimonónicas (Gould 1984: 145) y que estas investigaciones fueron comunes en algunas colonias británicas (Mumford y Smith 1938); en colonias portuguesas, a través de las denominadas Misiones Antropológicas (Augusto 1950); y en Sudáfrica (Brookes 1944). En el caso de la colonia española, estas investigaciones fueron subvencionadas por la administración colonial con una finalidad aplicada: establecer la capacidad mental de la población africana, con el fin de disponer medidas políticas al respecto. $Y$ en esta dirección apuntan las investigaciones dirigidas por Vicente Beato y Ramón Vilarino (1944), y Ricardo Ibarrola (1949). El primer estudio se realiza con la finalidad - según sus autores- de conocer científicamente el papel que los nativos podrían ejercer en el desarrollo económico de la colonia y, en consecuencia, buscar "la organización de una política colonial española racionalmente desarrollada" (Beato y Vilarino 1944: 10). Los autores deciden emplear para esta investigación los controvertidos tests de Yerkes; criticados como método científico, tanto en Estados Unidos, como en Europa (Gould 1984; Harris 1989). Sin detenernos en los defectos y errores técnicos de estas investigaciones ${ }^{10}$, sus conclusiones no hacen más que confirmar el apriorismo de otras anteriores realizadas por los mismos autores: los africanos no poseen aptitudes psíquicas ni biológicas para la asimilación $\mathrm{y}$, por lo tanto, las salidas profesionales a las que pueden aspirar se limitan a aquellas profesiones que requieran fuerza muscular (Beato y Vilarino 1944: 97). La segunda investigación dirigida por Ricardo Ibarrola desarrolla estos mismos prejuicios para llegar a conclusiones similares: los africanos poseen una capacidad igual o superior a la de los españoles en las facultades "prácticas". Sin embargo, en lo que se refiere

${ }^{10}$ Entre estos errores se encuentran la poca importancia concedida al contexto socio-cultural y al dominio del castellano por parte de los participantes (Sánchez 1998). 
a facultades intelectuales "más elaboradas", necesarias para ocupar altos cargos en la dirección de la colonia, el estudio confirma una acentuada inferioridad:

La deducción que en el aspecto práctico y con relación a la posibilidad educativa de estos niños indígenas podemos establecer es que hallándose mal dotados para la elaboración del pensamiento abstracto y las operaciones mentales de orden lógico y mostrando en cambio buenas aptitudes de inteligencia práctica y habilidad manual se debiera, una vez completada su instrucción primaria que forzosamente ha de ser muy somera, orientarles en su mayor parte hacia los oficios manuales para los cuales ofrecen un nivel mental suficiente y en los que podrían ser extraordinariamente útiles (Ibarrola 1951: 28).

La utilización en estos estudios de tests como los de Yerkes incide en los mismos errores y falacias científicas de investigaciones previas llevadas a cabo en Estados Unidos para justificar la discrimación legal de la población afroamericana en el sistema socio-político norteamericano (Gould 1984; Harris 1989). En contextos coloniales, como en el caso español o portugués, se traduce en intentos científicos que pretenden justificar evidentes intereses políticos y económicos (Sánchez 1998) ${ }^{11}$. Ante este tipo de argumentos científicos, los defensores de la asimilación mantienen sus posicionamientos negando y contrarrestando tales evidencias científicas. Heriberto R. Álvarez se pronuncia contra el esencialismo y determinismo de tales posturas: "No podemos hacernos eco de gratuitas afirmaciones que tantas veces hieren nuestros oídos, las cuales hacen suponer una inferioridad congénita en la raza aludida" (Álvarez 1948: 21); para justificar a continuación la capacidad de asimilación de los africanos con los argumentos ambientalistas del antropólogo y administrador colonial francés Delafosse:

El defecto de hablar del negro o estudiarle siempre con relación a nuestra raza blanca y con la tesis "a priori" que sienta a la suposición que ésta es el prototipo de civilización [...] Ello no es producto precisamente de un defecto atávico, congénito, de imposible corrección, sino muy especialmente del medio en que se ha desarrollado (Álvarez 1948: 22).

${ }^{11}$ Estas investigaciones recibirán igualmente sus críticas en estudios llevados a cabo dentro de la colonia en la década de los cincuenta. Entre ellos, las de Ave María Vila, médica con larga trayectoria en Guinea, que critica el etnocentrismo de la investigación de Ibarrola; fundamentalmente al no considerar el contexto cultural de los fang (Vila 1952: 58-59). Jesús de la Serna Burgaleta, tras una investigación realizada en 1955 con la población infantil de la colonia, afirma que la baja puntuación obtenida por los niños africanos en investigaciones anteriores debía interpretarse como una consecuencia de sus diferencias culturales (Serna 1956). 
El administrador español conocía las críticas vertidas contra las investigaciones psicométricas llevadas a cabo décadas antes en Estados Unidos:

[...] pero estas diferencias, como muchos autores han sostenido, en apariencia raciales, pueden provenir de factores culturales consecuentes de las condiciones en que los grupos en que se trata han vivido más que de factores intrínsecos de la raza o nacionalidad examinada ( Álvarez 1948: 416).

Y apoyándose, igualmente, en las tesis culturalistas de Margaret Mead, propone la elaboración de tests específicos para el "grupo racial negro" (Álvarez 1948: 425). Álvarez manifiesta así su preocupación por el perjuicio que estas doctrinas podrían suponer para el modelo educativo que pretendía establecer. De ahí que se proponga aplicar una política asimilacionista en su sentido más dirigista; consecuente con la ideología del nacional-catolicismo imperante:

Sentadas tales teorías y tomadas como buenas, lo que se hace necesario para lograr nuestro objetivo es, en definitiva, la propagación de una cultura dirigida y adaptada en consonancia a los intereses espirituales y humanos que defendemos (Álvarez 1949: 391).

Con todo, el modelo asimilacionista planteado por Álvarez se muestra incapaz de superar un evolucionismo cultural que, en cierto sentido, reproduce los mismos paradigmas decimonónicos de los estadios culturales planteados por Morgan (1964). En este sentido, parte de la idea de que los africanos, aunque con capacidad para la asimilación, se encuentran en un estadio evolutivo cultural primario. De ahí la necesidad de poner en práctica una intensa política educativa que posibilite un acelerado desarrollo cultural hacia el estadio máximo del desenvolvimiento cultural representado por la civilización cristiana (Álvarez 1949: 415). Al contar con el apoyo del gobernador Bonelli y de los misioneros de la colonia, Heriberto R. Álvarez logra implantar una política educativa según sus tesis peculiares sobre la asimilación. Con todo, y a pesar de sus pretensiones, su política asimilacionista no logra los éxitos que esperaba si tenemos en cuenta el número de africanos que alcanza el estatus de emancipado antes de 1959 (Pélissier 1964; Liniger-Goumaz 1989).

\section{DE LA ASIMILACIÓN AL RACISMO}

La política de asimilación fue en el caso español, como en el resto de las colonias europeas, laxa y poco efectiva hasta que se formula la 
provincialización para evitar la independencia de las colonias. La asimilación fue, no sin peculiaridades y ambigüedades, el modelo político en las colonias de los países latinos (España, Portugal, Francia y Bélgica), mientras que Gran Bretaña aplica, con grandes contradicciones, la política del . gobierno indirecto o dual que tiene en cuenta, con ciertos límites, patrones culturales autóctonos. En el caso francés, el interés y los esfuerzos por hacer efectiva una política de asimilación fueron nulos (Lewis 1962: 152). Precisamente, uno de los objetivos iniciales de la asimilación en la política francesa fue la creación de un controlado y limitado número de auxiliares indígenas, con el fin de suplir la falta de este tipo de personal en las colonias. Aunque la formación de auxiliares era vital para el funcionamiento administrativo de las colonias, los administradores y educadores franceses habían determinado limitar el número de personas asimiladas, con el fin de prevenir un potencial que pudiera considerarse molesto y peligroso para el mantenimiento del sistema. De ahí que hasta la Segunda Guerra Mundial fueran limitadas las oportunidades de trabajos importantes para los africanos (Sabatier 1978: 247). Según Sabatier, a pesar del mito del "francés negro" y la retórica de la asimilación, los franceses nunca tuvieron intención de crear élites indígenas que pudieran competir con los franceses ni africanos tan afrancesados que pudieran trabajar efectivamente como mediadores entre la administración colonial francesa y la población africana "no-educada" (Sabatier 1978: 248). En el caso portugués, cuya política indígena fue similar a la española, la administración parece preocupada porque la educación de los africanos pueda representar alguna amenaza para sus intereses coloniales, de ahí que se mostrara renuente a adoptar un programa masivo de educación dirigido a los africanos. Hasta el comienzo de la década de 1960, sólo un uno por ciento de la población africana de las colonias portuguesas había alcanzado el estatuto de asimilado (Cabral 1965: 153). En el caso español en Guinea Ecuatorial, los emancipados hasta la desaparición del sistema del patronazgo en 1959 fueron pocos y cuidadosamente elegidos: africanos totalmente españolizados, profesionales y propietarios que apenas representaban el uno por ciento de la población (Liniguer-Goumaz 1989: 21). Sólo aquellos que, en cierta manera, demostraron su lealtad y rentabilidad al sistema colonial tuvieron garantizada su emancipación:

Y puesto que ahora está sobre el tapete la "emancipación" de los indígenas de nuestra Colonia, hágase mediante una compensación, por ejemplo un servicio público, algo comparable con el servicio militar o el servicio social que todos deben hacer en España. El servicio público debía realizarse en una edad en que el rendimiento compensase los gastos que la nación hiciese con ellos (Fernández 1951: 79-80). 
La política indígena española, en cuanto fundamentada en principios evidentemente etnocéntricos, tuvo significativas similitudes con el apartheid sudafricano en dos aspectos importantes. En primer lugar, en cuanto que el elemento que interviene para establecer la división de la población de la colonia se fundamenta en los mismos supuestos biológicos que la Ley de Población (Population Act), reduciendo a todos los africanos a una categoría racial inferior fundamentada en la pigmentación de la piel (Zaragoza 1963: 65). Y en segundo lugar, en cuanto que a través de generalizaciones supraétnicas se abstraen las diferencias socio-culturales de las distintas poblaciones de las colonias; enajenándolas de sus derechos fundamentales de origen. En este sentido, los africanos autóctonos (bubis, fang, ndowes...) son discriminados - como en el apartheid sudafricano- con respecto a la población de origen europeo y equiparados a los africanos inmigrantes temporales de otros territorios. Sin embargo, en el caso español, y a diferencia del sudafricano, la estructura biotipológica estratificada no tenía porqué ser teóricamente determinante, ya que, al fin y al cabo, la asimilación era teóricamente el único elemento valorativo de la emancipación; de tal manera, que la categoría de no-emancipado no tendría que ser definitiva. Sin embargo, lo cierto es que su carácter transitorio permanece ambiguo hasta 1959. En realidad, la emancipación supuso un estado de restricción para la mayoría de los africanos en su capacidad de obrar y en la negación de su identidad, propiedad y libertad. La temporalidad se convirtió en un estatus permanente, y la emancipación supuso una conquista alcanzada únicamente por muy pocos: trabajadores contratados durante dos años en un establecimiento agrícola o industrial con salario equivalente o superior a 5.000 pesetas; funcionarios al servicio del Estado o de los Consejos de Vecinos en una categoría igual o equivalente a la de auxiliar indígena; y titulados con diplomas profesionales o académicos expedidos por universidades, institutos y otros centros oficiales (Patronato 1955: 7).

Esta política indígena propició de hecho una segregación política y económica de la población de la colonia y, como en el apartheid, la exclusión de una mayoría convertida en minoría discriminada. Por otra parte, como ya hemos señalado, aunque lo que realmente se impuso fue la asimilación - acelerada tras la provincialización - en la colonia se desarrollaron doctrinas racistas que, en alguna medida, influyeron en la discriminación política y económica que sufrió gran parte de la población durante el periodo colonial.

El racismo fue, por lo tanto, una manifestación social presente no sólo por la existencia de manifestaciones de sentimientos y actitudes de tipo heterofóbico, sino, y, fundamentalmente, por la existencia de doctrinas y 
políticas que intentaron dar por natural la inferioridad del otro mediante fundamentos científicos (Gould 1984; Moreno 1994), determinando, asimismo, el lugar administrativo, educativo y laboral que las poblaciones nativas debían ocupar dentro del sistema. En el caso de las investigaciones científicas realizadas en la colonia, sus conclusiones parecen favorecer, como en el caso de los estudios psicométricos, los intereses político-económicos de la minoría dominante. No en vano, el mayor problema para la explotación económica de los territorios fue siempre la escasez de braceros para las explotaciones agrícolas de Bioko y las industrias madereras de Río Muni; situación que ocasionaba bastante incertidumbre entre los inversionistas y entre los colonos propietarios de fincas y explotaciones madereras. Con todo, no dejan de sorprender en este sentido proclamas, frente a la política de asimilación propuesta por Álvarez, invitando a una política indígena de "analfabetismo y machete" (Báguena 1950: 99).

Como conclusión podría afirmarse que la política indígena española en Guinea Ecuatorial se apoyó, como otras políticas coloniales en el continente, sobre construcciones coloniales como la del bomo infantilis (Comaroff 1991), construcciones ideológicas que sirvieron incluso para legitimar políticas coloniales divergentes. En el caso español, "la minoría de edad" juega un importante papel para justificar, en cualquiera de los posicionamientos ideológicos, el sistema colonial. El resultado de esta infantilización fue la normalización de la segregación de gran parte de la población africana obligada a depender del Patronato de Indígenas hasta su desaparición. Sólo con la provincialización de los territorios en 1959, se reconocieron los derechos de ciudadanía de todos los africanos de la colonia y curiosamente se desarrolló una política de asimilación mucho más efectiva de lo que había sido hasta entonces (Negrín 1993).

\section{BIBLIOGRAFÍA CITADA}

Álvarez García, H. 1948. Historia de la acción cultural en la Guinea Española. Madrid: IDEA.

ARBeló Corbelo, A. 1943. Contribución al estudio de la población indígena en los territorios españoles del Golfo de Guinea. Madrid: Imp. Diana Artes Gráficas.

ASAD, T. (ed.). 1992. Antropology and the Colonial Encounter. Atlantic Highlands, New Jersey: Humanities Press.

Augusto, A. 1950. "Inteligência global dos Macuas". Congreso da Associaçao Portuguesa para o Progresso das Ciências 5: 423-431.

Banciella, J. 1940. Rutas del Imperio. Fernando Poo y Guinea. Madrid: Lib. General Victoriano Suárez.

Baguena Corella, L. 1950. "Algunas costumbres pamues". Archivo IDEA 11: 81-100.

BARTRA, R. 1996. El salvaje en el espejo. Barcelona: Destino. 
BEATO y VILARINO, R. 1944. La capacidad mental del negro. Madrid: Dirección General de Marruecos y Colonias.

BONELli, J. 1947. Concepto del indigena en nuestra colonia. Madrid: IDEA

Brookes, E. 1944. "African Mental Ability". African Affairs 43: 171-177.

CABral, J. 1965. "Portuguese Colonial Policy (Angola and Mozambique)". Africa Quarterly 5: $153-171$.

Calvo Calvo, L. 1997. "África y la Antropología española: la aportación del Instituto de Estudios Africanos". RDTP LII (2): 169-186.

CASTRO, M. y M. CAlle. 1992. Origen de la colonización Española de Guinea Ecuatorial (1777-1860). Valladolid: Universidad de Valladolid.

Chamberlain, C. 1978. "The Migration of the Fang into Gabon During the Nineteenth Century: A New Interpretation". International Journal of African Historical Studies 11: 429-456.

COMAROFF, J. y J. 1991. Of Revelation and Revolution. Christianity, Colonialism, and Consciousness in South Africa. Chicago: The University of Chicago Press.

Cornevin, M. 1980. Apartbeid: poder y falsificación de la bistoria. Nueva York: Unesco. CurTIN, Ph. 1964. The Image of Africa. Wisconsin: The University of Wisconsin Press. FERNANDEZ, J. 1982. Bwiti: An Etbnograpby of the Religious Imagination in Africa. Princeton: Princeton University Press.

FERNÁNDEZ CABEZA, J. 1951. La persona pamue desde el punto de vista biotipológico. Madrid: IDEA

GALlO, D. 1988. Antropologia e colonialismo. O saber português. Lisboa: Editores Reunidos.

Gould, S. 1984. La falsa medida del bombre. Barcelona: Antoni Bosch editor.

HARRIS, M. 1989. Introducción a la Antropología General. Madrid: Alianza.

IBARrola, R. 1951. "Aportación al estudio del nivel mental de los indígenas de la Guinea". Archivos IDEA 18: 7-29.

Iglesias, A. 1947. Politica indigena en Guinea. Madrid: IDEA.

KING, A. 1997. "Introduction: Spaces of Culture. Spaces of Knowledge", en A. King (ed.), Culture, Globalization and the World-System. Contemporary Conditions for the Representation of Identity: 1-18. Minneapolis: University of Minnesota Press.

KoTTAK, C. 1994. Cultural antbropology. Nueva York : McGraw-Hill.

LECLERC, G. 1973. Antropología y Colonialismo. Madrid: Alberto Corazón.

LEWIS, M. 1962. "One Hundred Million Frenchmen: The 'Assimilation' Theory in French Colonial Policy". Comparative Studies in Society and History 4: 129-153

LiNIGUER-Goumaz, M. 1989. Small is not always Beautiful. The Story of Equatorial Guinea. Otowa, New Jersey: Barnes \& Noble Books.

MAlgesinI, G. 1998. Cruzando fronteras. Migraciones en el sistema mundial. Madrid: Fundación Hogar del Empleado.

MORENO, P. 1994. "Cerraduras de sombras: racismo, heterofobia y nacionalismo", en J. Contreras (comp.), Los restos de la inmigración. Racismo y pluriculturalidad: 217247. Madrid: Talasa.

Morgan, L. H. 1964. Ancient society. Cambridge: Belknap Press of Harvard University Press.

MumFoRD, W. y C. SMITH. 1938. "Racial Comparations and Intelligence Testing". African Affairs 37: 46-57.

NEGRÍN FAJARDO, O. 1993. Historia de la Educación en Guinea Ecuatorial. El modelo educativo colonial español. Madrid: UNED. 
Patronato DE Indígenas. 1955. Datos para su bistoria. Madrid: Imprenta Hijos de R. Oviedo.

PAYNE, S. 1984. El catolicismo español. Barcelona: Planeta.

PÉlISSIER, R. 1964. Los territorios españoles de Africa. Madrid: CSIC.

-. 1980. "Autopsy of a Miracle". Africa Report 3: 10-14.

PERMUY, F. 1954. "El Patronato Indígena". La Guinea Española 42: 405-409.

Phelan, J. 1958. "The influence of Religion on the History of the New World". The Americas 14: 502-506.

Portes, A. y R. Rumbau. 1996. Immigrant America. A Portrait. Berkeley, Los Angeles, London: University of California Press.

Pujadas, T. 1983. La Iglesia en la Guinea Ecuatorial. Rio Muni. Barcelona: Editorial Claret.

TODD, E. 1996. El destino de los inmigrantes. Asimilación y segregación en las democracias occidentales. Barcelona: Tusquests Editores.

SABATIER, P. 1978. "Elite' Education in French West Africa: The Era of Limits, 1903-1945". The International Journal of African Historical Studies 11: 247-266.

SÁNCHEZ Molina, R. 1998. Las imágenes de los fang en los expedicionarios, misioneros $y$ africanistas españoles durante la época colonial (1858-1959). Tesis Doctoral. Barcelona: UNED

Serna Burgaleta, J. 1956. El niño guineano. Estudio antropométrico y psicotécnico. Madrid: IDEA

SundiATA, I. K. 1990. Equatorial Guinea. Colonialism, State Terror, and the Search for Stability. Boulder: Westview Press.

VIlla CoRo, A. M. 1952. Natalidad, mortalidad, morbilidad y desarrollo del niño pamue en la Guinea Continental española. Madrid: Revista de Sanidad e Higiene Pública.

ZARAgOzA, J. M. 1963. Ensayo sobre el derecho de los pamues de Río Muni. Madrid: IDEA. 